\title{
FORSE-1: A Positionally Regulated Epitope in the Developing Rat Central Nervous System
}

\author{
Shubha Tole, Zaven Kaprielian, Susan Ker-hwa Ou, and Paul H. Patterson \\ Division of Biology, California Institute of Technology, Pasadena, California 91125
}

\begin{abstract}
We designed a protocol to identify cell surface molecules expressed in restricted spatial patterns in the developing central nervous system (CNS) that might be regulated by regionally restricted transcription factors. The immunogen was a membrane fraction from NT2/D1 embryocarcinoma cells that were induced to differentiate into neurons and upregulate Hox gene expression in response to retinoic acid. One monoclonal antibody (mAb), FORSE-1, specifically labels the rostral rat CNS from the earliest stages. Staining is observed in the rostral but not caudal neural folds of the embryo prior to neural tube closure. Staining is enriched in the forebrain as compared to the rest of the CNS, until E18. Between E11.5 and E13.5, only certain areas of the telencephalon and diencephalon are labeled. Later, up to E17.5, FORSE-1 labeling is specifically restricted to the telencephalon, where a correlation with mitotic activity is apparent: the ventricular zone labels with FORSE1 , while the cortical plate is negative. The staining of the neuroepithelium is intensified by acetone fixation, which also reveals, between E11.5 and E13.5, a dorsoventrally restricted, FORSE-1-positive region of the spinal cord. After E18, the entire CNS is labeled, through adulthood. The mAb labels the surfaces of dissociated, living cells. Other, nonCNS areas of FORSE-1 labeling are nasal and otic placodes, nasal epithelium, nasal glands, and early (E9.5-10.5) endoderm. mAb FORSE-1 recognizes an epitope present on both a high-molecular-weight ( $>200 \mathrm{kDa}$ ) proteoglycan from embryonic and early postnatal brain, and on a $80 \mathrm{kDa}$ doublet that is restricted to the CNS in the aduit.

These findings suggest the FORSE-1 antigen as a candidate cell surface molecule for mediating regional specification from the earliest stages of CNS development.

[Key words: forebrain, cyclophosphamide immunosuppression, dorsoventral, position, proteoglycan, NT2/D1, rostrocaudal]
\end{abstract}

The development of the vertebrate CNS is a complex process during which the neural tube gives rise to a variety of divergent neural structures. A critical issue is how these differences are

\footnotetext{
Received May 3, 1994; revised July 18, 1994; accepted July 25, 1994.

We thank Dr. Didier Stainier for the $52 \mathrm{G} 9 \mathrm{mAb}$, and Andrew Furley for helpful discussions leading to this experimental approach. We also thank Drs. Karen Allendoerfer, Lisa Banner, and Sue McConnell for offering useful comments on the manuscript, and Bob Turing, Richard Gomez, Ben Sewell, Lance Brown, Ella McClanahan, Jim Staub, Theo Steiner, Alice Edel, and Le Hanh Dinh from the Graphic Arts facility at Caltech for their assistance with the illustrations. This project was supported by grants from the Lucille P. Markey Charitable Trust, the NINDS, and the Amyotrophic Lateral Sclerosis Association to P.H.P., an NRSA from the NINDS to Z.K., and a Helen G. and Arthur McCallum fellowship to S.T.

Correspondence should he addressed to P. H. Patterson at the above address. Copyright (c) 1995 Society for Neuroscience 0270-6474/95/150957-13\$05.00/0
}

generated. In the hindbrain, for example, the positions of the transient folds of the rhombomeres are correlated with the rostral limits of expression of several HoxB genes (Krumlauf et al., 1987; Graham et al., 1988; Hogan et al., 1988; Schughart et al., 1988; Bogarad et al., 1989; Frohman et al., 1990; Vogels et al., 1990; Hunt et al., 1991) as well as Hox A and D genes (Krumlauf, 1993). The spatial overlap of these genes suggested a role in defining axial position and cell identity, and disruption of Hox gene expression leads to alterations in cell migration and fate (Chisaka and Cappechi, 1991; Lufkin et al., 1991; Chisaka et al., 1992). Limited information is available concerning candidate downstream molecules. Hox 2.4 and 2.5 differentially regulate, in vitro, a construct containing the promotor of NCAM (Jones et al., 1992), and the highly polysialated form of NCAM is enriched at rhombomere boundaries (Lumsden and Keynes, 1989). Antigens bearing the HNK-1 epitope are also specifically present in odd-numbered rhombomeres in the hindbrain (Kuratani, 1991). These and other surface/extracellular molecules could play a role in giving cach rhombomere a unique identity.

Regional specification of the developing forebrain, in contrast, is complicated by the fact that different areas have very diverse architectonic characteristics. In the mammalian forebrain, the olfactory bulb consists of three-layered paleocortex; in the telencephalon, the medial walls give rise to one-layered archicortex, the lateral walls give rise to six-layered neocortex, and the basal telencephalon forms the striatum; the diencephalon gives rise to thalamic structures. Thus, these various regions may not represent simple modifications of iterated segmental domains.

While the Hox genes are not expressed rostral to the hindbrain, homeobox-containing and other classes of transcription factors have recently been found to overlap in interesting patterns in the developing forebrain. BF-1, Dlx-1, Dlx-2, and TTF-1 are expressed in regions of the olfactory bulb and telencephalon (Lazzaro et al., 1990; Porteus et al., 1991; Price et al., 1991; Robinson et al., 1991; Tao and Lai, 1992); Dlx-1, Nkx2.2, and TTF-1 demarcate overlapping regions in the diencephalon (Price et al., 1992); Otx-1, Otx-2, Emx-1, and Emx-2 are expressed in nested domains extending from the forebrain to the hindbrain (Simeone et al., 1992); MASH-1 is expressed in a subpopulation of neural precursors in spatially restricted domains in the CNS (Lo et al., 1991). These various patterns are suggestive of a role in defining regional identity, and some of their boundaries are consistent with proposed rostrocaudal and dorsoventral domains in the forebrain (Bulfone et al, 1993). Results of functional perturbation experiments are not yet available, however, and little is known about the downstream targets of these genes. It seems likely that critical intercellular interactions in the developing forebrain will involve secreted, cell surface, and extracellular matrix molecules. 
Table 1. Injection schedule for Balb/c mice

Day Treatment

Day 1

Day 2

Day 3

Day 8

Day 14

Day 22

Day 23

Day 26
$300 \mu \mathrm{g} \mathrm{RA(-)}$ plus $0.2 \mathrm{ml}$ RIBI adjuvant (RIBI Immunochem) plus cyclophosphamide (100 mg/kg body weight, i.p.)

Cyclophosphamide only (i.p.), same dose

Cyclophosphamide only (i.p.), same dose

Serum screening

$300 \mu \mathrm{g} R(+)$ plus $0.2 \mathrm{ml}$ RIBI adjuvant (i.p.)

Serum screening

Boost \#2 mouse with $100 \mu \mathrm{gA}(+)$ (intrasplenic injection)

Fuse \#2 mouse, $1.65 \times 10^{8}$ spenocytes were collected and fused with $6.2 \times 10^{7}$ HL1-653 myeloma cells (Kohler and

Milstein, 1975); cells were plated at $2.2 \times 10^{5}$ cells $/$ well
In order to identify cell surface molecules that are expressed in restricted distributions during CNS development and that may be responsive to position-specifying transcription factors, we generated monoclonal antibodies (mAbs) against the membrane fraction of retinoic acid-induced, human embryocarcinoma (NT2D1) cells. In response to retinoic acid, these cells express neuronal differentiation markers as well as certain Hox genes (Andrews, 1984; Mavilio et al., 1988; Simeone at al., 1990). We reasoned that neuronal differentiation, coupled with specific Hox gene expression, could result in the production of downstream, cell surface antigens with interesting positional distributions. We used cyclophosphamide immunosuppression (Matthew and Patterson, 1983; Matthew and Sandrock, 1987; Ou et al., 1991) against the membranes of uninduced NT2D1 cells to bias the immune response in favor of novel membrane antigens that are induced by retinoic acid treatment.

One mAb generated from this fusion, FORSE-1 (forebrainsurface-embryonic), labels the embryonic rat forebrain very specifically. Within the forebrain, FORSE-1 has a restricted staining pattern that demarcates subregions of the telencephalon and diencephalon that have not been previously described. In this paper, we describe the immunohistochemical labeling pattern of FORSE-1 during development and the biochemical characterization of the antigens recognized by the $\mathrm{mAb}$.

\section{Materials and Methods}

Cell culture. Clone D1 of the NTERA-2 (referred to as NT2/D1) human EC cells were obtained from P. W. Andrews (The Wistar Institute of Anatomy and Biology). NT2/D1 cells were maintained at high density

\section{Table 2. Serum screening results (days 8 and 22)}

\begin{tabular}{lcl} 
& RA( $(-)$ titer & RA $(+)$ titer \\
\hline $\begin{array}{l}\text { Day } 8 \text { screen } \\
\text { Control }\end{array}$ & \\
Exp 1 & $1: 500$ & \\
Exp 2 & $<1: 50$ & \\
Day 22 screen & $<1: 50$ & \\
Control & & \\
Exp 1 & $1: 5000$ & $1: 5000$ \\
Exp 2 & $1: 100$ & $1: 100$ \\
\end{tabular}

Sera samples were tested against the $\mathrm{RA}(-)$ and/or $\mathrm{RA}(+)$ membrane/cytoskclctal preparations on dot blots. The control mouse received the antigen injection without cyclophosphamide. For Exp 1 and Exp 2, experimental mice received the antigen injection plus cyclophosphamide. The Exp 2 mouse was selected for fusion because it showed a difference in titer against the RA(+) versus the $\mathrm{RA}(-)$ preparations. in Dulbecco's modified minimal essential medium supplemented with $10 \%$ fetal bovine serum. Cultures to be exposed to retinoic acid (RA) were established by plating a trypsinized single-cell suspension of undifferentiated NT2/D1 cells at a density of $10^{6}$ cells per $75 \mathrm{~cm}^{2}$ tissue culture flask (Andrews, 1984; Andrews et al., 1984). RA (10 mM solution in dimethyl sulfoxide, all-trans; Sigma Chemicals) was added to a final concentration of $10^{-5} \mathrm{M}$. The medium was changed with fresh medium containing RA every $48 \mathrm{hr}$. Differentiation was monitored by morphological changes in the cultures, and by the proportion of cells positive for the glycolipid surface marker A2B5 (Andrews et al., 1990). The RA-induced immunogen (see below) was generated from cells that had been exposed to $10^{-5} \mathrm{M}$ RA for 2 weeks.

Preparation of the immunogen. Undifferentiated and RA-induced NT2/D1 cells were harvested by rolling $3 \mathrm{~mm}$ diameter glass beads (P. W. Andrews, personal communication) over the surface of confluent cell layers in a few milliliters of medium. The intact cells were then centrifuged at $1000 \mathrm{rpm}$ for $10 \mathrm{~min}$ in an IEC HN-SII tabletop centrifuge. The cell pellets were then resuspended in homogenization buffer [50 mM Tris-HCl (pH 7.4), $50 \mathrm{~mm} \mathrm{NaCl}, 5$ mM EDTA, 2 mм EGTA] containing five protease inhibitors: $1 \mathrm{mM}$ phenylmethylsulfonyl fluoride, $20 \mu \mathrm{g} / \mathrm{ml}$ aprotinin, $20 \mu \mathrm{g} / \mathrm{ml}$ turkey egg white trypsin inhibitor, $2 \mathrm{~mm}$ benzamidine, and $5 \mathrm{mM} N$-ethylmaleimide, and homogenized with a Polytron (Brinkman Instruments Co.). The homogenates werc centrifuged at $1000 \mathrm{rpm}$, as described above, to remove nuclei and cell debris. The resulting supernatants were then centrifuged at $100,000 \times g$ for 1 $\mathrm{hr}$ in a Beckman $70 \mathrm{Ti}$ rotor. The pellets were resuspended in homogenization buffer and washed twice by centrifugation at $100,000 \times g$ for $1 \mathrm{hr}$ and subsequent resuspension. The final pellets were resuspended in homogenization buffer. This material, which will be referred to as the membrane/cytoskeletal fraction, was either used immediately or frozen at $-80^{\circ} \mathrm{C}$ until further use. All procedures were carried out at $4^{\circ} \mathrm{C}$. Protein was determined by the method of Lowry et al. (1951) or by the BCA protein assay (Pierce Chemical Co.).

Immunization and $m A b$ production. Balb/c mice were injected with either undifferentiated NT2/D1 membrane/cytoskeletal fractions [RA(-)] or RA-induced NT2/D1 membrane/cytoskeletal fractions [RA $(+)]$ according to the schedule described in Tables 1 and 2. The myeloma cells used for the fusion were HL1-653 (Taggart and Samloff, 1983).

Immunohistochemistry. Pregnant female Sprague-Dawley rats were obtained from Simonsen Laboratories (Gilroy, CA). The morning after the day of mating is designated as day 0.5 . Whole embryos, embryonic, and adult tissues were directly frozen, without fixation in O.C.T. (Tissue-tek), on dry ice. Sections $(10 \mu \mathrm{m})$ were cut using a Bright cryostat (Hacker Instruments, Inc.), and placed on gelatin-coated slides. After air drying, the sections were either stained immediately or stored at $-80^{\circ} \mathrm{C}$. Acetone fixation, when performed, was carried out using acetone for $10 \mathrm{~min}, 0^{\circ} \mathrm{C}$, prior to the staining procedure given below.

The sections were preadsorbed with $2 \%$ goat serum in PBS, and incubated in primary antibody (hybridoma supernatant) for $1 \mathrm{hr}$ at room temperature (RT), washed twice with PBS, and then incubated in the secondary antibody that was either FITC conjugated (FITC-goat antimouse IgM, Tago Inc., used at 1:100 in PBS) or biotinylated (Vector Mouse IgM ABC-peroxidase kit). In the latter case, the Vector ABC procedure was followed without blocking endogenous peroxidase, using a negative control (no primary antibody) to assess background staining.

Cultures were stained live for FORSE-1, similar to the procedure for sections, using FITC-labeled secondary antibody. FITC-labeled cultures 
and slides were mounted in glycerol containing n-propyl gallate $(8 \mathrm{mg} /$ $\mathrm{ml}$ final concentration, dissolved in $0.1 \mathrm{M}$ Tris- $\mathrm{HCl}, \mathrm{pH} 9$ ). Peroxidaselabeled slides were mounted in Aquamount (BDH Ltd., Poole, England). Slides were observed and photographed using a Zeiss ICM 405 microscope. Kodak Tri-X Pan 400 film was used for fluorescence pictures, and Kodak Plus-X Pan 125 or Kodak Gold 100 film for brightfield pictures.

Tissue culture. E16 telencephalic lobes were dissected in $\mathrm{Ca}^{2+} / \mathrm{Mg}^{2+}$ free Hanks-A solution, and incubated in $1 \mathrm{mg} / \mathrm{ml}$ collagenase (Worthington Biochemical Corp.) in Hanks-A for $1 \mathrm{hr}$ at $37^{\circ} \mathrm{C}$. The enzyme was then blocked by the addition of serum. Cells were washed free of collagenase by pelleting at $1000 \mathrm{rpm}$ in a tabletop centrifuge and resuspending in culture medium (repeated twice). Undissociated clumps were broken up by gentle trituration using a flame-polished Pasteur pipette that had been preadsorbed with serum. Cells were plated on polylysine-laminin-coated tissue culture dishes (Corning, $35 \mathrm{~mm}$ ). L15 $\mathrm{CO} 2$ medium (Hawrot and Patterson, 1979) supplemented with $10 \%$ FBS was used as the tissue culture medium. Cells were cultured for 16 hr.

Preparation of tissue fractions. Tissues from various age rat embryos, and postnatal and adult rats were dissected and immediately frozen on dry ice. The postnatal and adult rats were killed by asphyxiation with carbon dioxide. Upon thawing, tissues were homogenized by hand or with a Polytron (Brinkman Instruments Co.) in homogenization buffer. The homogenates were centrifuged at $1000 \mathrm{rpm}$ for $10 \mathrm{~min}$ to remove nuclei and cell debris. The supernatants were centrifuged at $100,000 \times$ $g$ for $1 \mathrm{hr}$. The supernatants resulting from this centrifugation were either used immediately or frozen at $-80^{\circ} \mathrm{C}$, and will be referred to as the soluble fractions. Pellets were resuspended in homogenization buffer and washed twice by centrifugation at $100,000 \times g$ for $1 \mathrm{hr}$. The final pellets were resuspended in homogenization buffer. These preparations, which will be referred to as the membrane/cytoskeletal fractions, were either used immediately or frozen at $-80^{\circ} \mathrm{C}$. In some cases, the membrane/cytoskeletal fractions were also solubilized in nonionic detergent. This was done by first recentrifuging these fractions at $100,000 \times g$ for $1 \mathrm{hr}$. The pellets were then thoroughly resuspended by homogenization in homogenization buffer containing $1 \%$ Triton X-100 or NP40, and centrifuged again at $100,000 \times g$ for $1 \mathrm{hr}$. The resulting supernatants contain the nonionic detergent-solubilized proteins.

Enzymatic digestions. Soluble fractions of embryonic, early postnatal, and adult CNS tissues solubilized with $1 \%$ NP40 were directly digested with the following glycosidases: chondroitinase $\mathrm{ABC}(2.0 \mathrm{U} / \mathrm{ml}$, from proteus vulgaris; Sigma), hyaluronidase $(500 \mathrm{U} / \mathrm{ml}$, from leeches; Sig$\mathrm{ma})$, heparinase I ( $100 \mathrm{U} / \mathrm{ml}$, from Flavobacterium heparinum; Sigma), keratanase $(2.5 \mathrm{U} / \mathrm{ml}$, from pseudomonas species; Sigma), endoglycosidase $\mathrm{H}(0.5 \mathrm{U} / \mathrm{ml}$, recombinant $E$. coli; Boehringer Mannheim), neuraminidase $(0.2 \mathrm{U} / \mathrm{ml}$, from Vibrio cholerae; Boehringer Mannheim), and $\mathrm{N}$-glycosidase F $(4.0 \mathrm{U} / \mathrm{ml}$, from Flavobacterium meningosepticum Boehringer Mannheim). In each case, approximately $100 \mu \mathrm{g}$ of protein in the homogenization buffer described above (including protease inhibitors) was digested for $12-16 \mathrm{hr}$ at $37^{\circ} \mathrm{C}$. As controls, identical protein samples were treated in exactly the same way, but did not include enzyme. At the end of the incubation period all samples were diluted $1: 1$ with $2 \times$ SDS-PAGE reducing sample buffer (20\% glycerol, $4 \%$ SDS, $0.13 \mathrm{~m}$ Tris, $2 \% \beta$-mercaptoethanol, and 0.01 bromophenol blue, $\mathrm{pH}$ 6.8) to terminate the digests.

Electrophoresis and immunoblotting. One-dimensional SDS-PAGE was performed as described by Laemmli (1970) in $1.5 \mathrm{~mm}$ thick, $7 \%$ polyacrylamide slab gels. All samples were diluted $1: 1$ with $2 \times$ nonreducing or reducing sample buffer (see above) prior to loading. Nonreducing sample buffer is identical to reducing sample buffer, but does not contain $\beta$-mercaptoethanol. Immunoblots were performed as described by Kaprielian and Patterson (1993), with the modifications listed below. First, proteins present within the resolving as well as the stacking portions of the gels were routinely transferred to nitrocellulose. Primary antibody incubations were for $5 \mathrm{hr}$ at room temperature or $12-16 \mathrm{hr}$ at $4^{\circ} \mathrm{C}$, with either mAb FORSE-1 or mAb 52G9 (undiluted hybridoma supernatant). The nitrocellulose filters were incubated with goat antimouse IgM affinity-purified antisera conjugated to peroxidase (Chemicon, Int.) and diluted 1:200, to detect primary antibody binding.

\section{Results}

\section{$m A b$ production and screening}

We used the cyclophosphamide immunosuppression method to bias the immune response towards membrane antigens on reti-
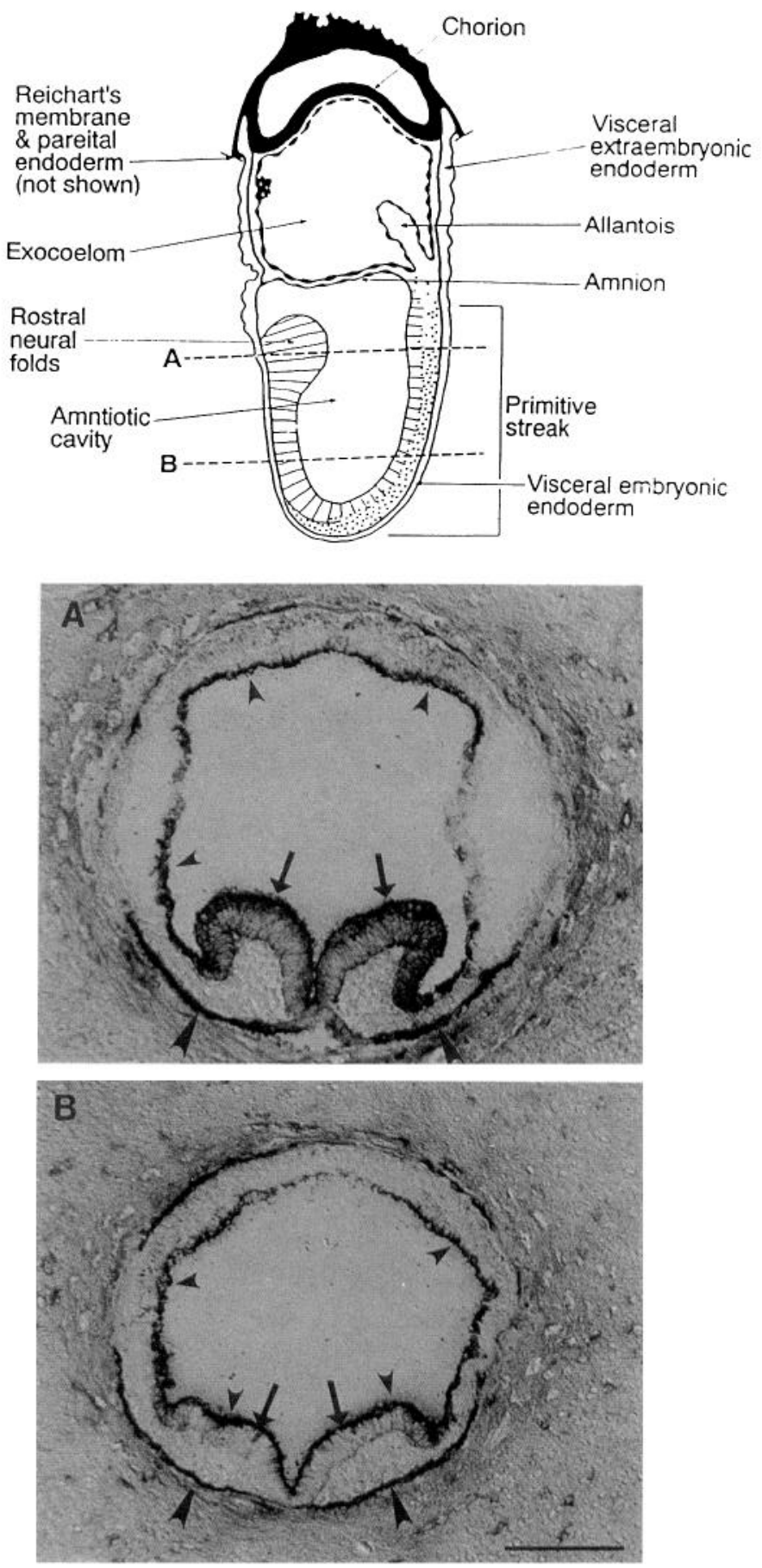

Figure 1. FORSE-1 labeling in the E9.5 rat embryo. Sections of E9.5 rat embryos stained with FORSE-1 show label in the rostral neural folds (arrows), while the primitive streak at the caudal end of the embryo is unlabeled $(A)$. In addition, the dorsal surface of the entire embryonic and extraembryonic ectoderm (small arrowheads), and the endoderm (large arrowheads) labels with FORSE-1. This labeling is also present in a more caudal section $(B)$, where the neuroepithelium itself does not label (arrows point to neural folds). Scale bar, $200 \mu \mathrm{m}$.

noic acid-induced NT2D1 embryocarcinoma cells. Hybridoma supernatants were screened on frozen, sagittal sections of whole E14.5 and E18.5 rat embryos, postfixed with $1 \%$ paraformaldehyde. This protocol reflects a compromise between the need to preserve the integrity of the neural tissue through fixation and 

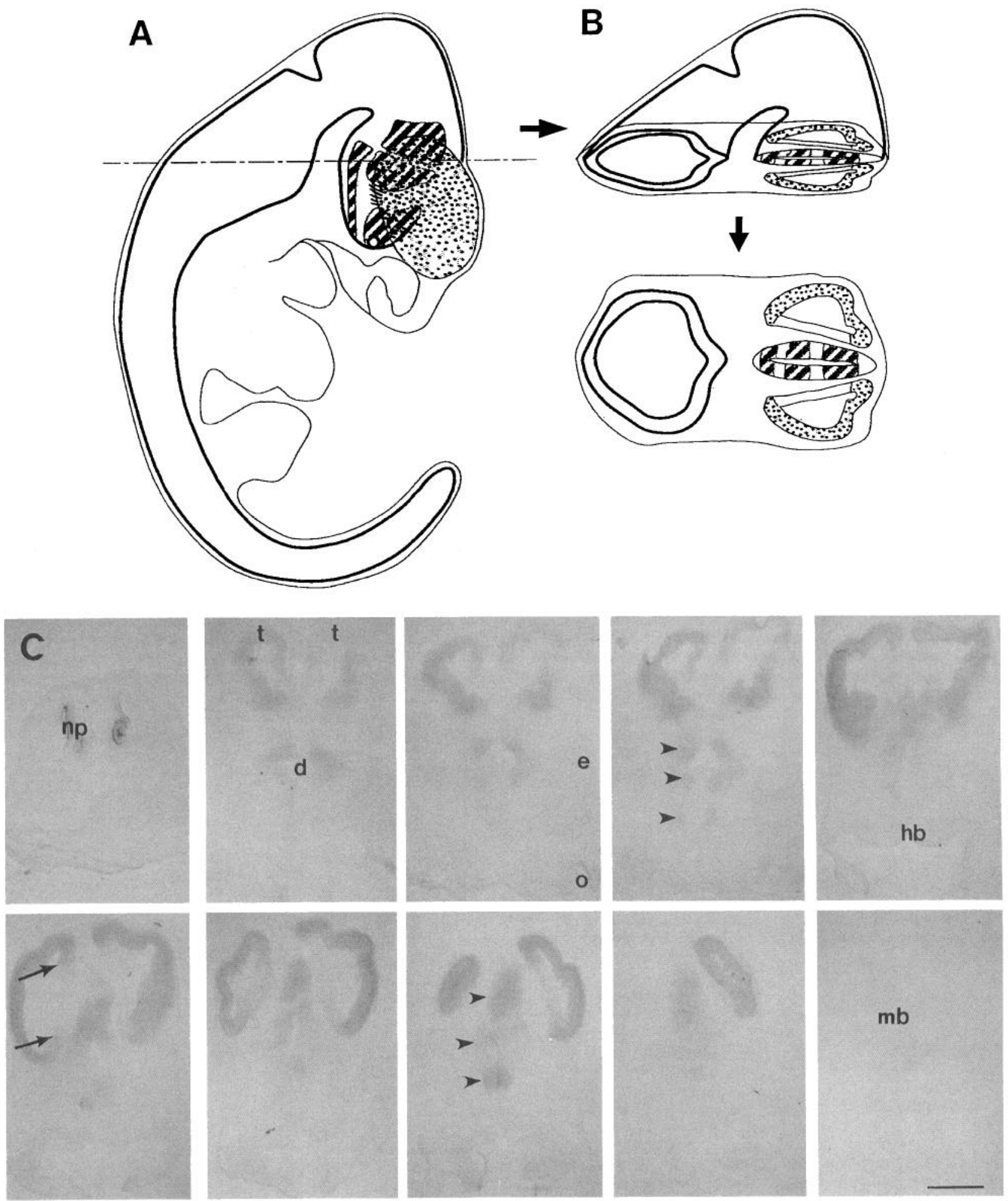

Figure 2, FORSE-1 labels the E12.5 CNS. A-C, A reconstruction of the labeling pattern of FORSE-1 in the E12.5 rat embryo. A, Schematic of a lateral view of an E12.5 embryo showing the CNS, and the staining pattern of FORSE-1 in the telencephalon (stipple) and diencephalon (hatches). This pattern was reconstructed from serial sections cut as in $B . B$, A cutaway view of $A$, showing the plane of sectioning, and a representative section after staining with FORSE-1. $C$, Serial sections of the head of an E12.5 embryo cut as shown in $B$, displayed in order from upper left to lower right, stained with FORSE-1, show labeling of the nasal pits $(n p)$, telencephalon $(t)$, and diencephalon $(d)$, but not the midbrain $(m b)$ and hindbrain $(h b)$. Within the telencephalon, a restricted region of the medial walls remains unlabeled (arrows), and the diencephalon shows three FORSE-1-positive regions (arrowheads) separated by FORSE-1-negative regions. $o$ is the otic placode that shows FORSE-1 staining. The developing eye $(e)$ does not label with FORSE-1. Scale bar, $1 \mathrm{~mm}$. 


\section{Cresyl violet FORSE-1(unfixed) FORSE-1(acetone)}

A
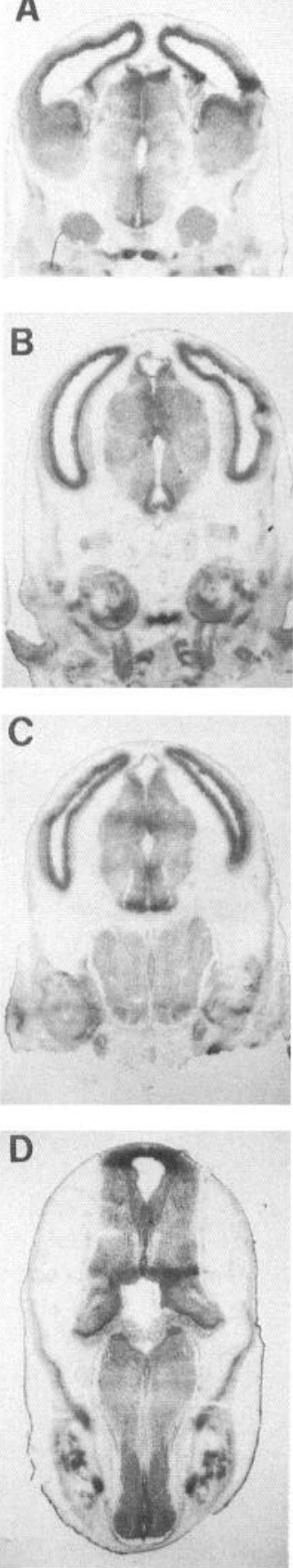
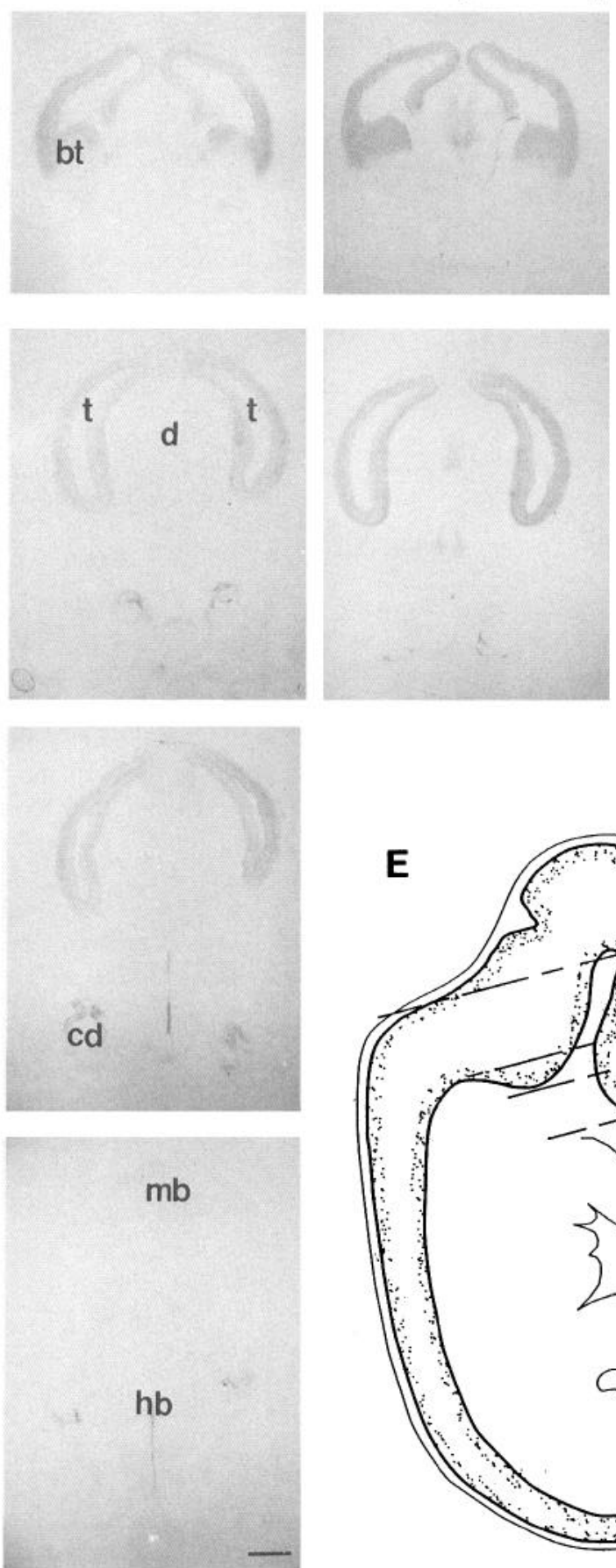
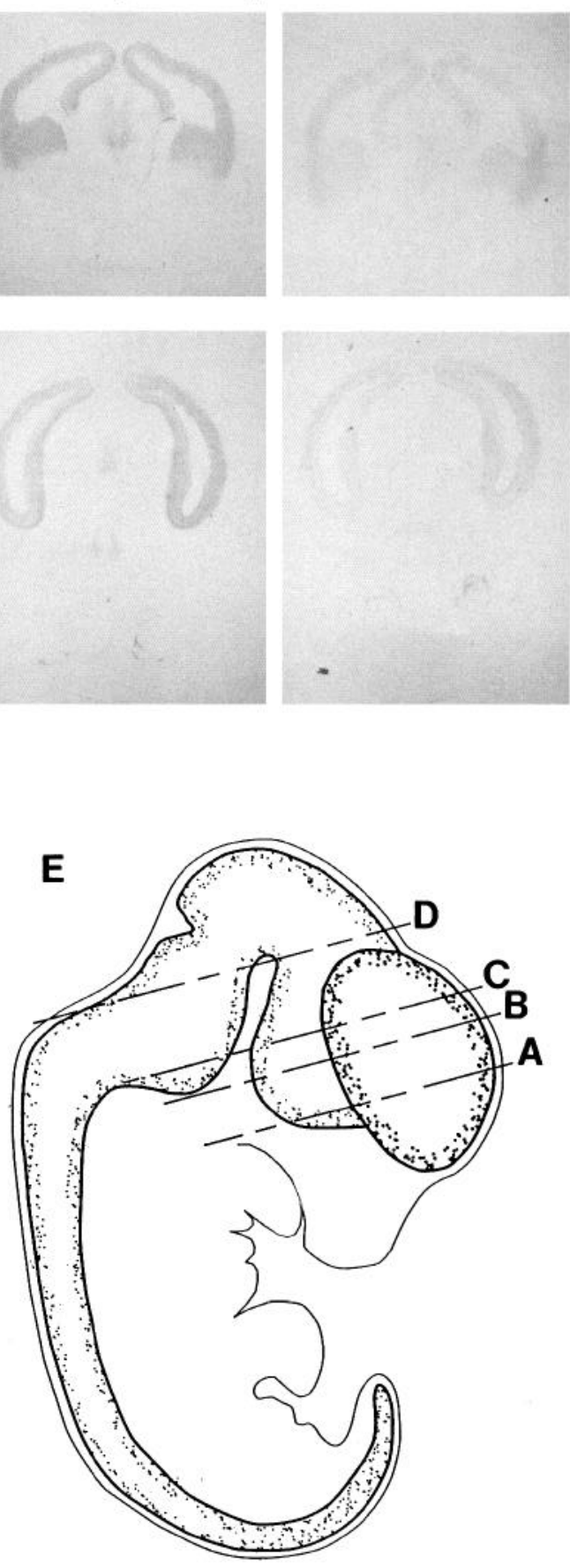

Figure 3. FORSE-1 labels E15 rat telencephalon. Rows $A-D$ each show serial sections of an E15 rat embryo, through the brain, cut as shown in $E$, stained with cresyl violet, FORSE-1 (unfixed sections), FORSE-1 (acetone-fixed sections), and 52G9. $A$ and $B$ show the telencephalon and diencephalon $(d)$. In the telencephalon, FORSE-1 staining is present throughout the neuroepithelium, except for the outer region of the basal telencephalon $(b t)$. The diencephalon does not label with FORSE-1 at this age. The cochlear ducts $(c d)$ also label with FORSE-1. Acetone fixation enhances but does not alter this labeling pattern, except that a greater area of the basal telencephalon shows label, and minor areas of labeling appear along the ventricular zone of the diencephalon. 52G9 shows a labeling pattern very similar to FORSE-1, where the telencephalon, but not the diencephalon, and the cochlear ducts are stained. $C$ shows the telencephalon, diencephalon, and part of the hindbrain $(h b)$, and $D$ shows the midbrain $(m b)$ and hindbrain. FORSE-1 does not label the diencephalon, midbrain, or hindbrain, except for label along the midline of the hindbrain. The spinal cord does not appear in these sections since the head of the embryo was frozen separate from the body in preparation for sectioning. Scale bar, $1 \mathrm{~mm}$. 

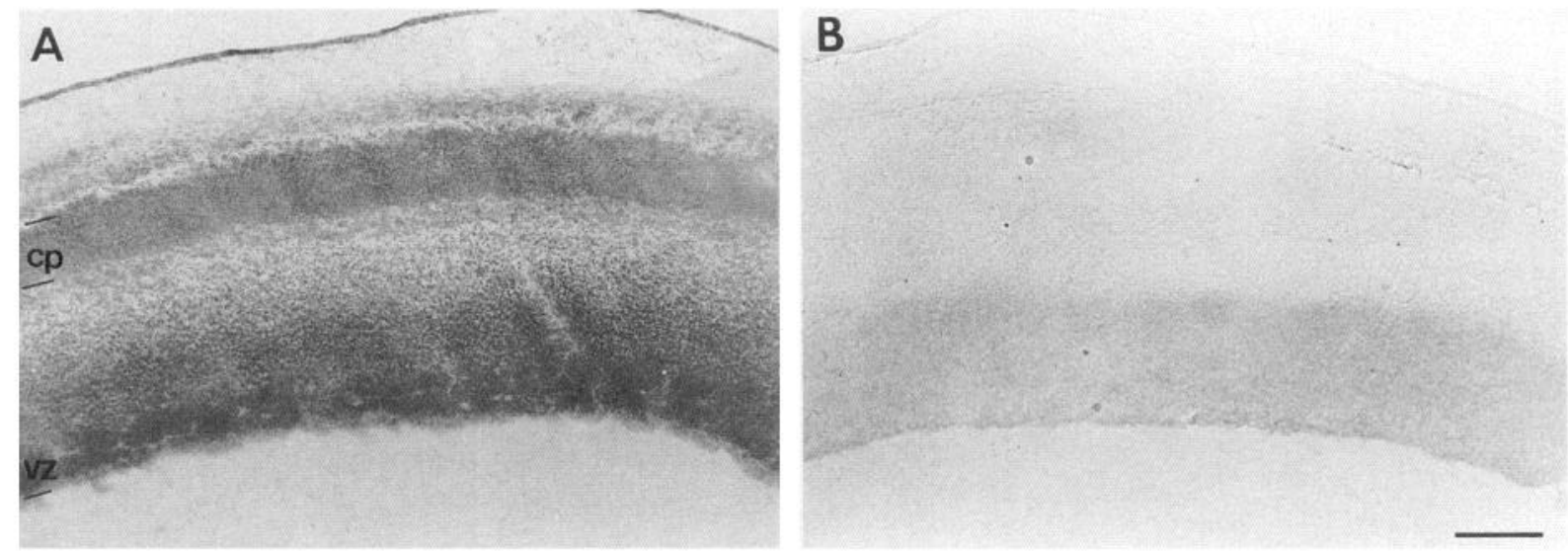

Figure 4. FORSE-1 labels E17.5 telencephalon. $A, B$, Serial transverse sections of an E17.5 rat brain, stained with cresyl violet ( $A$ ) and FORSE-1 $(B)$, showing the lateral wall of the telencephalic bulb, where FORSE-1 labels the ventricular zone $(v z)$ but not the cortical plate $(c p)$. Scale bar, $250 \mu \mathrm{m}$.

a desire to preserve the proteins in their native state for later identification and isolation (Patterson, 1992).

Of 960 hybridomas generated, approximately 640 supernatants contained mAbs and were screened on sections. Approximately half of these did not detectably label the CNS, and most of the other half labeled the entire CNS of one or both ages, with no positional differences in intensity. mAb FORSE-1 was selected for further study because it intensely labels the E14.5 forebrain, while the rest of the CNS appears negative.

FORSE-1 labeling in the CNS: forebrain, midbrain, hindbrain, and spinal cord

In rat embryos, FORSE-1 binding is detected as early as E9.5, labeling the rostral but not the caudal neural folds (Fig. 1). In addition, the dorsal surface of the entire embryonic ectoderm, and the endoderm label with FORSE-1. At E10.5, the prosencephalon, but not the remainder of the CNS, labels with FORSE-1 (not shown). The pharyngeal arches, Rathke's pouch, and gut label as well (not shown).

From E11.5 to E13.5, telencephalic and diencephalic staining
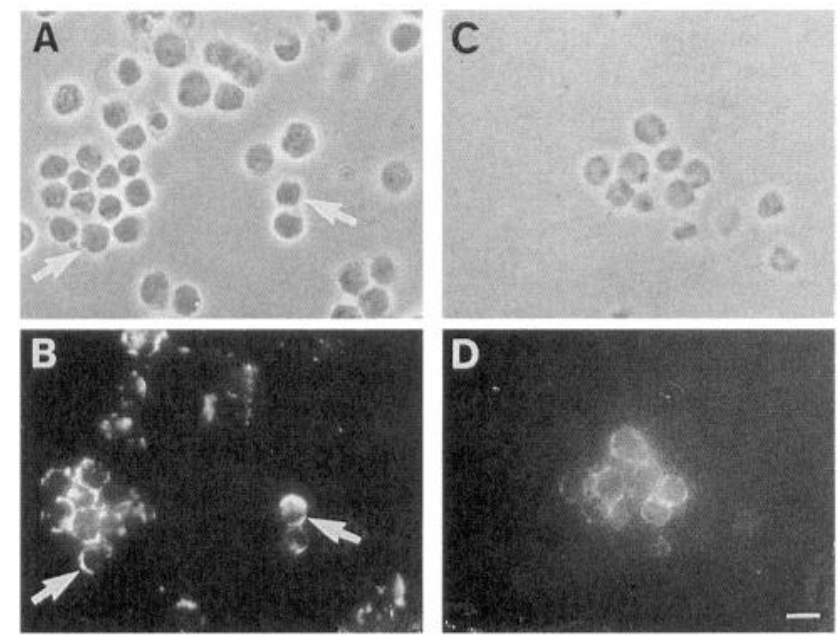

Figure 5. FORSE-1 labels freshly dissociated and cultured telencephalic cells. E16 telencephalic cells, freshly dissociated $(B)$ or cultured for $16 \mathrm{hr}(D)$, stained live with FORSE-1 show label on the surfaces of the cells. $A, C$, Phase-contrast photographs corresponding to $B$ and $D$, respectively. Scale bar, $10 \mu \mathrm{m}$. is clear (Fig. 2C). As summarized in a reconstruction of serial sections, restricted areas of these structures are FORSE-1 negative (Fig. 2B). The neuroepithelium is almost entirely proliferative at these stages, and hence has no distinguishable layers. The medial walls of most of the telencephalic bulbs are negative, while the rest of the telencephalon is positive, with the basal telencephalon (the ventral region of the telencephalic bulbs) being most intensely labeled. In addition, at these stages there appears to be a rostrocaudal gradient in the labeling of the lateral walls of the telencephalic vesicles where the rostralmost regions label less intensely than the caudal areas. In the diencephalon, there are discrete FORSE-1-positive areas separated by FORSE1-negative areas (Fig. 2C). The midbrain and hindbrain are sometimes weakly labeled at these stages, while the cord is consistently negative. Weak midbrain-hindbrain labeling is described under the later section on acetone fixation.

At E15, labeling is further restricted such that FORSE-1 binding in the telencephalon is maintained, with the basal telencephalon being most intensely labeled, while the diencephalon is FORSE-1 negative (Fig. 3). This contrasts with the pattern at earlier stages where both the telencephalon and the diencephalon are strongly labeled. The lateral and dorsal telencephalon displays label throughout the neuroepithelium. The basal telencephalon shows the most intense FORSE-1 label, but this label is in the ventricular and adjacent regions, while the outer region containing fibers and postmitotic cells is negative. The rest of the CNS is negative, except for labeling along the midline of the hindbrain (Fig. 3).

At E17.5, the rostrocaudal restriction of FORSE-1 labeling is similar to that at E15 in that only the telencephalon labels while the rest of the CNS is negative. Within the telencephalon, FORSE-1 now labels only the ventricular zone of dividing cells, while the cortical plate, where postmitotic neurons accumulate, is negative (Fig. 4). FORSE-1 labeling is seen on live, intact cells from the embryonic telencephalon, demonstrating that the antigen is on the cell surface (Fig. 5).

The olfactory bulb is FORSE-1 positive in the glomerular layer from E17.5 through postnatal life. The staining appears to be around the glomeruli, where the periglomerular cells, mitral cells, and interstitial tufted cells are located, and not within the glomeruli, where olfactory sensory axons make their synapses (Fig. 6A-D). By P10, this glomerular layer labeling is much 

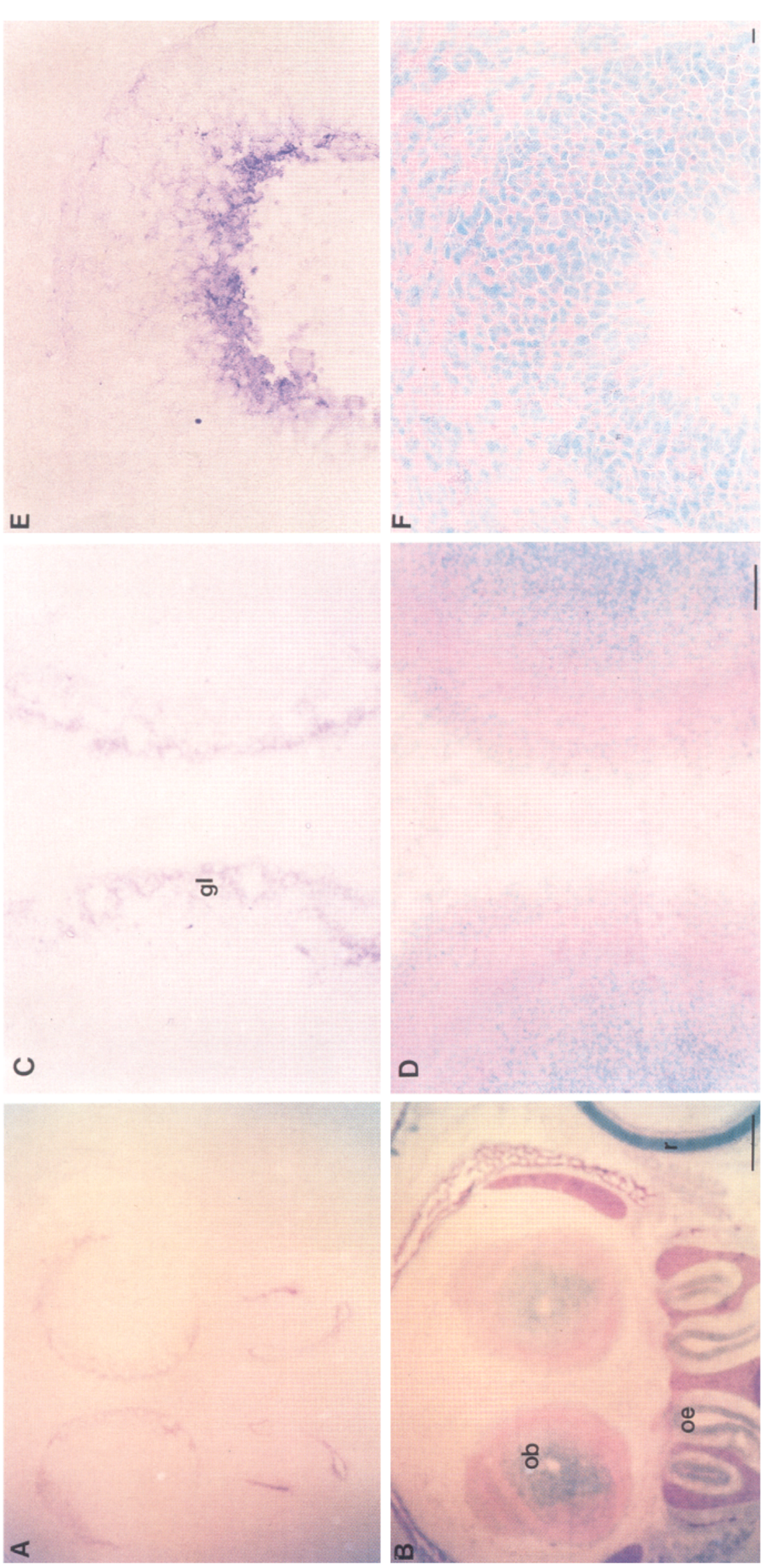

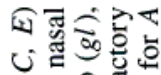

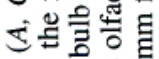

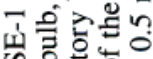
记尊 응형 芩 등 의 䛌

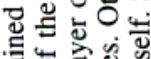

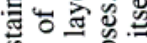
월 氜

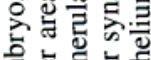

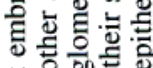

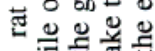
藏.

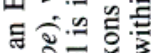
ङ 目 종 응 位 语语 이워

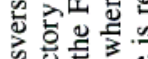
क

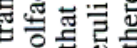

荌氙 क.

त कि

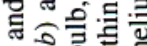
니의 돌을 응 0 늉명

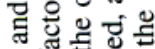

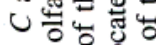

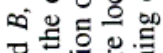

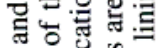

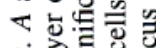
空 녈 을 要 등 에 0 的的

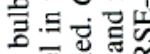
중워 热造

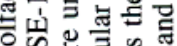

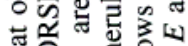

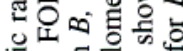
늘

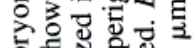

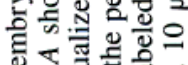

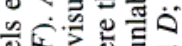
击 ब 0 专

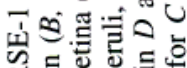
등 인.

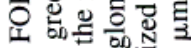

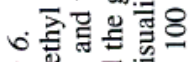
论

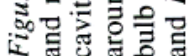


Figure 7. Effect of acetone fixation on FORSE-1 staining. Sections of E12.5 embryos through the forebrain $(f b)$, hindbrain $(h b)(A, C, E, G)$, and spinal cord $(s c)(B, D, F, H)$ were labeled with cresyl violet $(A, B)$, FORSE-1, no fixation $(C, D)$, diluted FORSE-1, acetone fixation $(E, F)$, and FORSE-1, acetone fixation $(G, H)$. On unfixed sections $(C, D)$, FORSE-1 labels only the forebrain, and not the hindbrain or spinal cord. Acetone fixation $(G, H)$ reveals label in the dorsal part of the midbrain and spinal cord, as well as an intensified staining of the forebrain. However, if acetone-fixed sections are labeled with diluted FORSE-1 $(E, F)$, the staining is essentially identical to $C$ and $D$, where only the forebrain is labeled. Scale bars: top row, $1 \mathrm{~mm}$; bottom row, $0.5 \mathrm{~mm}$.
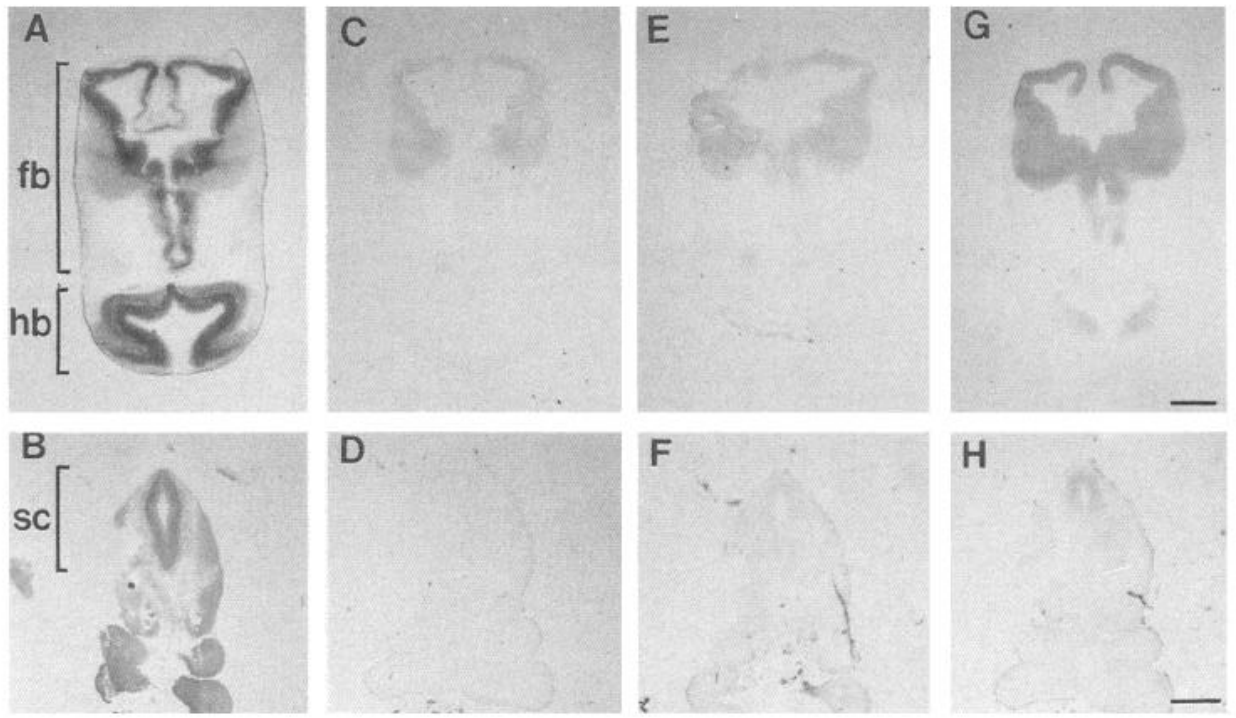

weaker. In the adult, the entire bulb is very weakly stained (not shown).

After E18.5, the FORSE-1 labeling pattern changes to one where many neurons in the CNS (except for the olfactory bulb, described above) are positive (not shown). This pattern remains into maturity. In the adult, the entire CNS has weak, patchy FORSE-1 labeling in the gray matter (not shown).

\section{FORSE-1 labeling in sensory structures}

The nasal pits are FORSE-1 positive from E11.5 through E14.5. At E15.5, the nasal epithelium, now thrown into folds, is FORSE-1 positive and continues to be so until birth, with binding mainly on the surface of the epithelium, lining the cavity, and to a lesser degree within the sensory epithelium itself (Fig. $6 E, F)$. Other nasal tissues, the lateral nasal, septal, and vomeronasal glands, are FORSE-1 positive from E17.5 through P10 (not shown). The vomeronasal organ itself is negative at all ages (not shown).

The retina is FORSE-1 positive upon acetone fixation, from E11.5 to E15 (not shown), but subsequently becomes negative until birth, when the inner nuclear layer of the retina is FORSE-1 positive. This staining continues in the adult (not shown).

The otic placodes are FORSE-1 positive from E10.5 onward (E12.5, Fig. 2C). From E15 to E17.5, the cochlear ducts stain with FORSE-1, primarily on the inner surface (Fig. 3). At birth, no labeling of otic structures is detected (not shown).

\section{Effect of acetone fixation on FORSE-1 labeling}

The FORSE-1 epitope is sensitive to paraformaldehyde, ethanol, and methanol fixation, therefore all of the data described above is from fresh-frozen sections, either unfixed or postfixed in $1 \%$ paraformaldehyde. Postfixation in acetone $\left(10 \mathrm{~min}, 0^{\circ} \mathrm{C}\right.$ or $-20^{\circ} \mathrm{C}$ ) remarkably intensifies the staining in areas that are FORSE-1 positive, while background staining (no $1^{\circ}$ antibody or irrelevant $\operatorname{IgM~} 1^{\circ}$ antibody) remains very light (Figs. 3, 7). The ability of acetone to increase the sensitivity of staining by the FORSE-1 antibody was tested using various dilutions of FORSE-1 supernatant on acetone-fixed sections, described below. In addition, we determined, using dissociated cells, that the subcellular localization of the staining with and without acetone fixation was similar; that is, acetone-fixed, dissociated E15 tel- encephalic cells appeared to show surface label, similar to the labeling of dissociated, live, unfixed cells (not shown).

We observed little change in the overall pattern of FORSE-1 staining after acetone fixation at any age except from E11.5 to E13.5. At E15, acetone fixation results in an intensification of telencephalic staining, as well as minor areas of diencephalic staining (Fig. 3). From E11.5 to E13.5, however, acetone fixation enables us to visualize FORSE-1 staining in a restricted part of the dorsal half of the entire CNS, from midbrain to the caudalmost spinal cord (Fig. 7). The dorsalmost area of the neural tube was consistently negative, as was the entire ventral half, resulting in a dorsoventrally restricted band of FORSE-1 staining. When the FORSE-1 mAb is diluted, however, the forebrain staining remains while, with increasing dilution, the spinal cord and then the midbrain and hindbrain staining become undetectable, even after acetone fixation (Fig. 7). This dilution result suggests a gradient of FORSE-1 antigen expression from high in the forebrain to low in the spinal cord. Such a gradient is supported by immunoblots of subdivisions of the CNS at E12 (see Fig. 9 and following section). Acetone may modify the FORSE-1 epitope, resulting in better binding of the $\mathrm{mAb}$, or allow the mAb improved access to the epitope.

\section{Identification of the FORSE-1 antigens}

To identify the FORSE-1 antigen, forebrains from E15 rat embryos were homogenized in low salt, and soluble and membrane fractions were separated by centrifugation. When the proteins in these two fractions were subjected to immunoblot analysis, FORSE-1 is found to bind a high-molecular-weight region, in both soluble and membrane-bound forebrain fractions, which does not migrate out of the stacking portion of the gel (Fig. 8A). There is no obvious staining of any proteins present within these two fractions when FORSE-1 is omitted from the incubation, and a variety of other antibodies generated from the same fusion do not label the high-molecular-weight region labeled by FORSE-1 (not shown). The heterogeneous and very large size of the FORSE-1-positive band suggest that the antigen is proteoglycan like (Herndon and Lander, 1990; Fryer et al., 1992; Maeda et al., 1992).

The nature of the FORSE-1 antigen in older animals was determined by performing immunoblots using protein fractions iso- 


\section{A. FORSE-1}

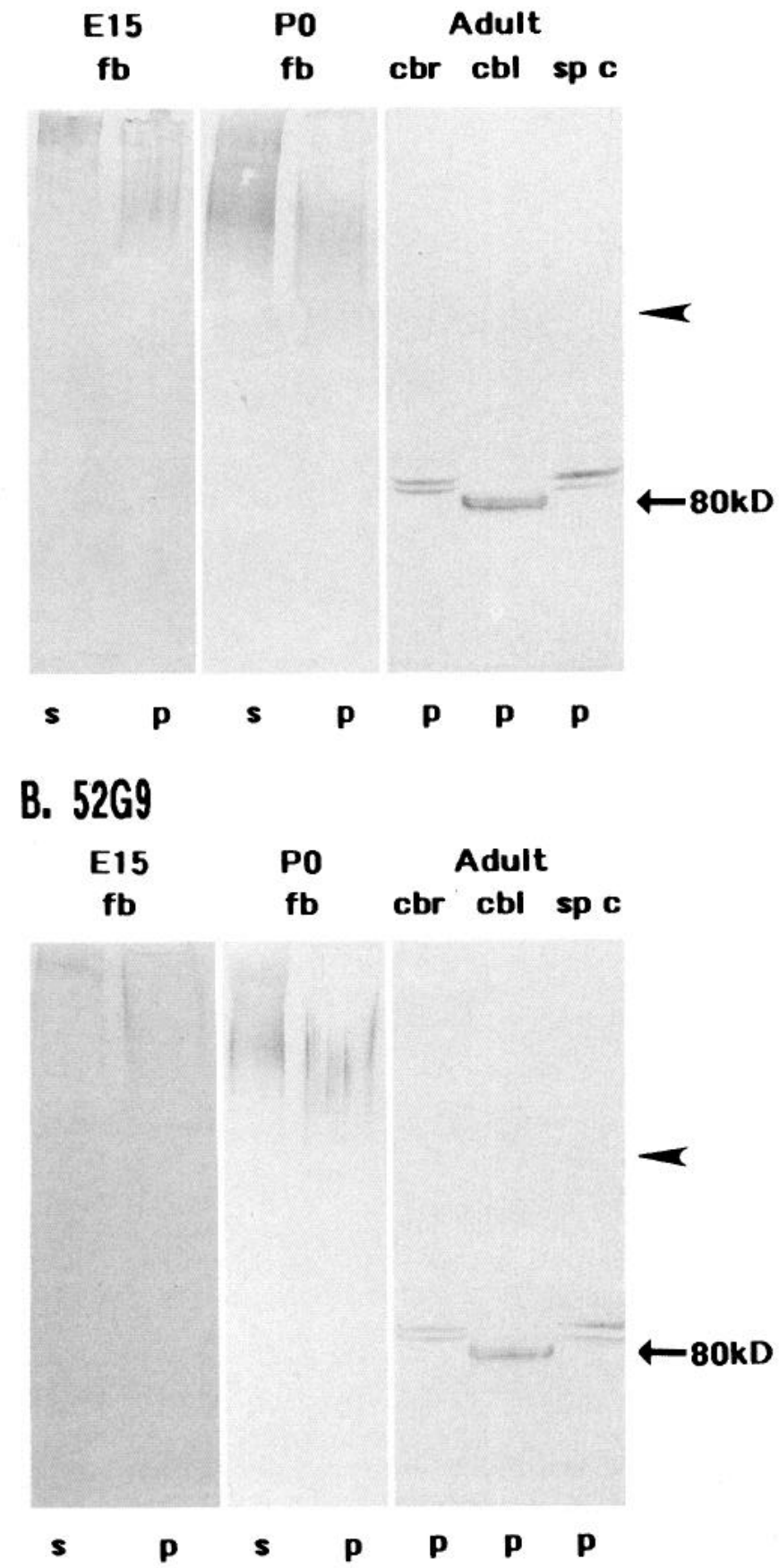

Figure 8. FORSE-1 and $52 \mathrm{G} 9$ both recognize a proteoglycan in the embryonic and newborn rat forebrain, and regionally expressed $80 \mathrm{kDa}$ doublets in the adult CNS. Soluble $(s)$ and membrane/cytoskeletal $(p)$ protein preparations from E15 and P0 rat forebrains, as well as membrane/cytoskeletal fractions $(p)$ of adult rat cerebrum ( $c b r)$, cerebellum $(c b l)$, and spinal cord $(s p c)$, were subjected to SDS-PAGE and immunoblot analysis. $A$ shows the binding of mAb FORSE-1 to a proteoglycan in the embryonic and $\mathrm{P} 0$ forebrain, and to $80 \mathrm{kDa}$ doublets in the adult rat $c r b, c b l$, and $s p c$. B shows very similar binding of mAb 52G9 to essentially identical nitrocellulose transfers. Primary antibody binding was visualized with a peroxidase-conjugated goat anti-mouse IgM secondary antibody. Arrowhead represents border between stacking and running gels. lated from newborn (P0) forebrains and subregions of the adult CNS. While FORSE-1 binds similar high-molecular-weight regions in the soluble and membrane-bound fractions of the $\mathrm{P} 0$ forebrain, this labeling is completely absent in any of the adult brain fractions (Fig. $8 A$ ). FORSE-1 does, however, specifically label a doublet centered at about $80 \mathrm{kDa}$ in the membranebound, but not the soluble (not shown), fractions derived from the adult cerebrum and spinal cord, and a similar doublet that migrates slightly faster than $80 \mathrm{kDa}$ in the membrane fraction derived from the adult cerebellum (Fig. 8A). The adult antigens are likely to be integral membrane proteins as they are fully extracted from the membrane fractions by Triton X-100 and NP40 (not shown). These bands are not labeled when FORSE-1 is omitted from the incubation, nor are they stained by a variety of other antibodies generated in the same fusion (not shown). Consistent with our immunohistochemical results, there is no obvious binding to soluble or membrane-bound fractions derived from the following adult tissues: dorsal root ganglia, sciatic nerve, kidney, liver, and adrenal medulla (not shown). We also performed immunoblots using 52G9, a previously characterized mAb that labels the forebrain of rat embryos (Stainier et al., 1991). Surprisingly, we find these immunoblots (Fig. $8 B$ ) are essentially identical to those generated with FORSE-1 (Fig. 8A). Moreover, in the immunoblot analyses of the rostrocaudal distribution of the embryonic/P0 antigen, and the carbohydrate content of both the embryonic/P0 and adult antigens using FORSE-1 described below, identical results were obtained with 52G9 (not shown).

A stringent test of whether the high-molecular-weight, FORSE-1-immunoreactive species is, in fact, the antigen visualized immunohistochemically in the embryo, is to analyze its rostrocaudal distribution. To do this we generated soluble and membrane-bound fractions from E12.5 and E15 forebrain, midbrain and hindbrain, spinal cord, and body (minus spinal cord). Equal amounts of protein from each fraction were subjected to an immunoblot analysis using FORSE-1. At both these ages, the biochemically detected rostrocaudal difference in the distribution of the FORSE-1 epitope parallels the immunohistochemical results (Fig. 9A). In addition, FORSE-1 detects similar levels of the embryonic antigen in protein fractions derived from P0 forebrain, cerebellum, and spinal cord (Fig. 9B), consistent with the lack of an immunohistochemical rostrocaudal gradient at this age. These data taken together indicate that the embryonic FORSE-1 epitope most likely resides on a high-molecularweight, proteoglycan-like antigen.

The proteoglycan-like characteristics of the embryonic/P0 antigen prompted us to determine whether the FORSE-1 epitope is composed of amino acids or carbohydrate. To do this we digested soluble fractions of $\mathrm{P} 0$ rat forebrain with the following glycosidases: chondroitinase $\mathrm{ABC}$, hyaluronidase, heparitinase, keratinase, endoglycosidase- $\mathrm{H}$, neuraminidase, or $\mathrm{N}$-glycosidase $\mathrm{F}$, and performed an immunoblot analysis using mAb FORSE1. Chondroitinase $\mathrm{ABC}$ digestion yields a more tightly resolved, faster migrating (although still within the stacking gel) FORSE1 -immunoreactive species (Fig. 10). None of the other glycosidases affected the mobility of the antigen or the binding of mAb FORSE-1 (not shown). This result suggests that the embryonic/ $\mathrm{P} 0$ antigen is a proteoglycan that contains chondroitin sulfate.

The migration (highly resolved bands) and nonionic detergent extractability of the adult antigens are not proteoglycan like, but are rather suggestive of a membrane glycoprotein. To test this we digested membrane fractions of adult rat cerebellum (solu- 
A.

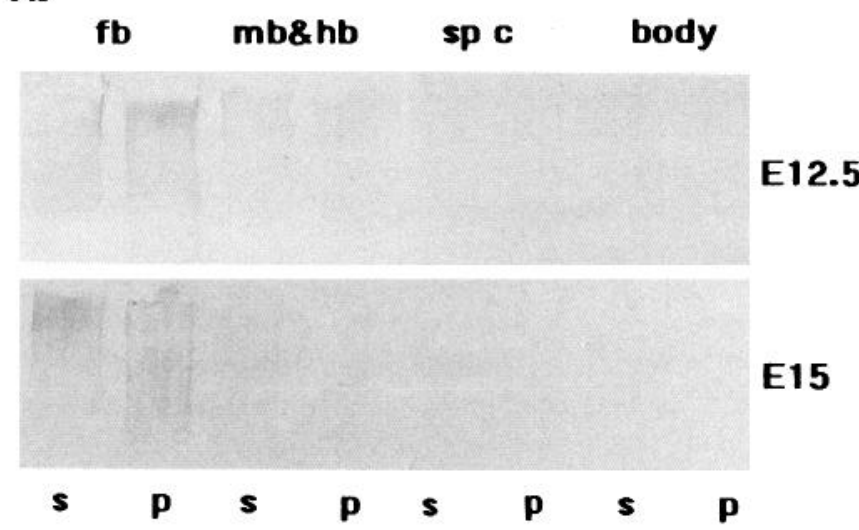

B.

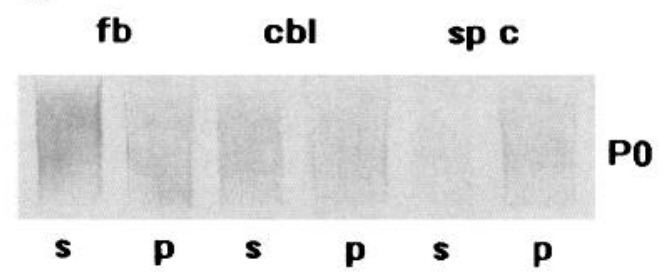

Figure 9. The FORSE-1 epitope on the proteoglycan is enriched in the rostral CNS early in embryonic development. Soluble $(s)$ and membrane/cytoskeletal $(p)$ protein fractions generated from various rostrocaudal regions of the E12.5 and E15, as well as the P0 CNS, were subjected to SDS-PAGE and immunoblot analysis. In $A$, the top panel shows the binding of FORSE-1 to the proteoglycan in the E12.5 protein fractions, while the bottom panel shows the binding to the E15 fractions. Both immunoblots show that the expression of the FORSE-1 epitope on the proteoglycan is enriched in the forebrain. Primary antibody binding was visualized with a peroxidase-conjugated goat anti-mouse IgM secondary antibody. $B$ shows the binding of FORSE- 1 to fractions of P0 rat CNS. Similar levels of the proteoglycan are detected in soluble as well as membrane/cytoskeletal fractions.

bilized with $1 \%$ NP40) with the same glycosidases used to characterize the embryonic antigen, and performed an immunoblot analysis with FORSE-1. While $N$-glycosidase F completely abolishes the binding of FORSE-1, none of the other glycosidases affect the mobility of the adult cerebellar antigen or the binding of FORSE-1 (Fig. 10; not shown). Identical results were obtained using adult cerebrum and spinal cord membranes (not shown). In all cases, FORSE-1 binding was eliminated whether the solubilized membranes were digested prior to SDS-PAGE or whether the nitrocellulose transfers of the resolved proteins were incubated with $N$-glycosidase F prior to the addition of the $\mathrm{mAb}$ (not shown). These data suggest that the adult antigens are glycoproteins that contain $\mathrm{N}$-linked high mannose, most likely in the form of hybrid and complex chains, and that the FORSE-1 epitope present on these antigens is composed of carbohydrate.

\section{Comparison with $m A b 52 G 9$}

We compared the immunohistochemical labeling pattern of FORSE-1 with that of 52G9 (Stainier et al., 1991). At all ages, consistent with the results of the immunoblot analysis (see above), the binding patterns of the two mAbs are identical, including the restricted labeling of the CNS (Fig. 3), nasal epithelia, and otic structures. Taken together, the immunohistochemical
Po

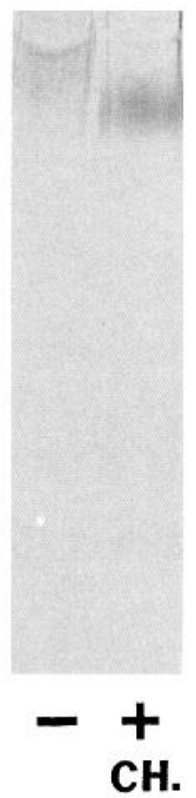

ADULT

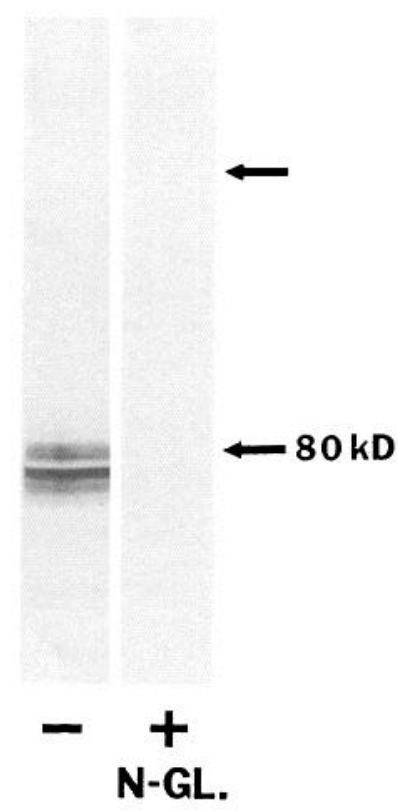

Figure 10. The FORSE-1 epitope is composed of carbohydrate. A, Equal amounts of soluble protein derived from the $\mathrm{P} 0$ rat forebrain were digested with chondroitinase $\mathrm{ABC}$ as described in the Materials and Methods. These digests, along with an undigested sample containing the same amount of protein, were subjected to SDS-PAGE and immunoblot analysis. FORSE-1 binds the proteoglycan in the control, undigested sample (-), and to a more resolved, faster migrating species in the sample digested with chondroitinase $\mathrm{ABC}(\mathrm{CH}) . \mathrm{B}, \mathrm{A}$ membrane/ cytoskeletal fraction derived from the adult rat cerebellum, solubilized with $1 \%$ NP40, was digested with $N$-glycosidase F $(N-G L)$ as described in the Materials and Methods. This digest and an undigested sample of the same protein fraction were subjected to SDS-PAGE and immunoblot analysis. $N$-glycosidase $\mathrm{F}$ completely eliminates the binding of mAb FORSE-1 to the $80 \mathrm{kDa}$ doublet. The upper arrow indicates the border between the stacking and running gels for both $A$ and $B$. Primary antibody binding was visualized with a peroxidase-conjugated goat antimouse IgM secondary antibody.

and immunoblot data indicate that FORSE-1 and 52G9 recognize epitopes on the same embryonic and adult antigens.

\section{Discussion}

Developmental expression of the FORSE-1 epitope in the CNS From the earliest stages, prior to closure of the neural tube, the FORSE-1 mAb exhibits a positionally restricted pattern of binding in the CNS. This suggests that the FORSE-1 antigens could play a role in patterning the neural tube. To understand the spatial regulation of the FORSE-1 antigens, the important features of the staining pattern are discussed separately below, and the data is summarized in Figure 11.

Proliferative neuroepithelium staining (E9.5-E17.5). That cells of dividing neuroepithelium specifically label with FORSE-1 is well demonstrated at E17.5 (Fig. 4), where staining is seen in cells of the ventricular zone but not the cortical plate.

Regional specificity in the E11.5-E13.5 forebrain. The forebrain contains some FORSE-1-positive and some FORSE-1-negative areas. From E11.5 to E13.5, the basal telencephalon and the lateral walls of the telencephalic bulbs label with FORSE-1 while the medial walls do not, and the boundaries between the positive and negative regions are sharp. In the diencephalon, FORSE-1 displays a unique labeling pattern which we have 


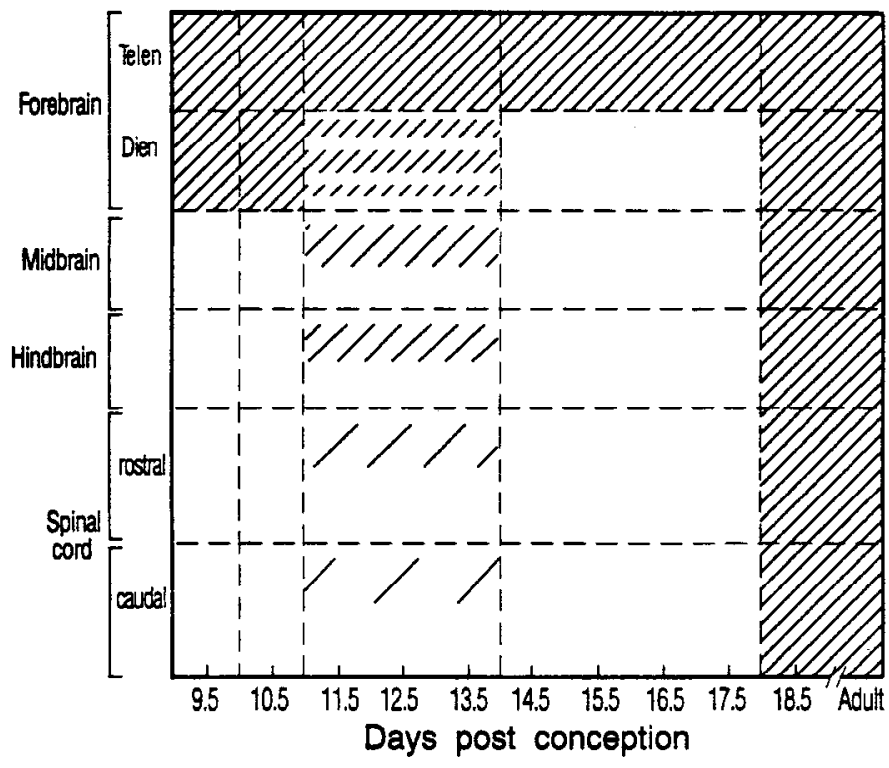

Figure 11. FORSE-1 labeling in the developing CNS. Hatching represents FORSE-1 staining, with greater densities reflecting higher labeling intensities. In the E11-E14 diencephalon, the three stripes of hatching represent the regional restriction described in Figure 2. In the E11-E14 midbrain, hindbrain, and spinal cord, the restricted region of hatching represents the staining observed in transverse sections, visualized after acetone fixation, as described in Figure 8.

compared in detail to several transcription factors (Tole and Patterson, 1995). The FORSE-1 labeling pattern is not identical to any of the known transcription factors in the early forebrain, and serves to further subdivide the developing forebrain.

Dorsoventral restriction in the midbrain-hindbrain-cord (E11.5-E13.5). Dorsoventral restriction within the forebrain is discussed above. Acetone fixation reveals a dorsoventrally restricted region of FORSE-1 labeling along the entire rostrocaudal extent of the CNS, from E11.5 to E13.5. This FORSE-1positive region lies in between a small dorsalmost area that is FORSE-1 negative, and most of the ventral half of the CNS. Transcription factors Pax 3 and 7 have similar dorsoventrally restricted distributions; Pax6, in contrast, appears to have a complementary distribution to that of FORSE-1 in the spinal cord. Members of the HoxB family all display spatially and temporally regulated patterns along the dorsoventral axis and show a striking dorsal restriction in the spinal cord between E12.5 and E14.5 in the mouse (Graham et al., 1991). Graham et al. suggest that the dynamic pattern of expression of these genes could reflect their role in conferring rostrocaudal identity to different classes of neurons as they are born in different locations along the dorsoventral axis. Dbx-1 is expressed in a narrow, dorsoventrally restricted stripe in the embryonic spinal cord ( $\mathrm{Lu}$ et al., 1992), and MASH-1 is transiently expressed in a dorsal region of the ventricular zone in the embryonic spinal cord (Lo et al., 1991). All these expression patterns reveal molecular differences in cells based on their dorsoventral position.

Widespread labeling of mature neurons (E18-adult). From late embryonic life through adulthood, the FORSE-1 antigen appears to no longer be subject to the spatial regulation discussed above. Instead, neurons throughout the CNS express the antigen, with local variations in intensity of labeling. This is consistent with the possibility that the FORSE-1 antigen has different roles in embryonic life and in maturity. The rostrocaudal regulation discussed above and the expression pattern from late embryonic life to adulthood together are reminiscent of the biphasic expression pattern of NCAM in the developing mouse CNS (BallyCuif et al., 1993). NCAM is first expressed in a rostrocaudal, position-dependent pattern, and then is expressed by almost all postmitotic neurons. It is significant that throughout embryonic and early postnatal life, the FORSE-1 antigen identified in the CNS is a high-molecular-weight proteoglycan (discussed further below), indicating that the change in expression pattern from a restricted to a widespread one does not appear to be accompanied by a change in the identity of the antigen. In the adult, however, FORSE-1 binds an $80 \mathrm{kDa}$ doublet.

\section{FORSE-1 antigens}

FORSE-1 recognizes an epitope on apparently distinct bands on immunoblots, and these are regulated with different developmental time courses. From E12.5 through early postnatal life, FORSE-1 binds a high-molecular-weight antigen in soluble and membrane-bound forebrain fractions that does not migrate out of the stacking gel even when subjected to SDS-PAGE under reducing conditions. A number of properties of this antigen indicate that it is likely to be a proteoglycan (Zaremba et al., 1989). The estimated molecular weight $(>200 \mathrm{kDa})$ of the FORSE-1-immunoreactive species and its broad, diffuse migration pattern are consistent with this antigen being a proteoglycan. The most compelling evidence on this point is provided by enzymatic digestion. That chondroitinase $\mathrm{ABC}$ digestion of soluble and membrane-bound forebrain fractions results in a tighter FORSE-1-positive band that migrates faster on SDS-PAGE strongly suggests that this antigen is a proteoglycan that contains chondroitin sulfate. The presence of the FORSE-1-immunoreactive proteoglycan in soluble as well as membrane-bound forebrain fractions is consistent with other studies that describe a similar subcellular distribution of proteoglycans (Zaremba et al., 1989; Oohira et al., 1988; Herndon and Lander, 1990; Maeda et al., 1992).

A number of recent studies have described the expression of developmentally regulated proteoglycans in the mammalian CNS (Herndon and Lander, 1990; Streit et al., 1990; Cole and McCabe, 1991; Fryer et al., 1992; Maeda et al., 1992), but none have reported a proteoglycan epitope whose expression is positionally and developmentally regulated as in the present case. That the biochemistry accurately reflects the distribution of the antigen detected immunohistochemically is especially clear at E12.5 and E15, where, consistent with the immunohistochemistry, immunoblot analysis clearly shows a forebrain-enriched distribution of the proteoglycan bearing the FORSE-1 epitope. During early postnatal development, in contrast, FORSE-1 labels sections of rostral and caudal CNS equally, and immunoblot analysis detects no positional difference in the expression of the proteoglycan. These results strongly suggest that we have correctly identified the antigen bearing the FORSE-1 epitope.

In immunoblots of membrane-bound fractions derived from the adult brain and spinal cord, FORSE-1 binds a doublet of proteins centered at about $80 \mathrm{kDa}$. These FORSE-1 antigens appear to be integral membrane glycoproteins and not proteoglycans, because they are completely solubilized by nonionic detergents, their mobility is not affected by enzymes such as chondroitinase $\mathrm{ABC}$, and $N$-glycosidase $\mathrm{F}$ treatment removes the FORSE-1 epitope. The latter result suggests that these antigens contain N-linked high mannose oligosaccharides, most likely in the form of hybrid and complex chains, and further indicates 
that the epitope recognized by FORSE-1 is composed of carbohydrate. This suggests that the FORSE-1 epitope on the embryonic antigen also contains $\mathrm{N}$-linked high mannose oligosaccharides. However, $\mathrm{N}$-glycosidase F treatment does not remove the epitope on the embryonic antigen, perhaps due to the enzyme's inability to access the appropriate site. This epitope is CNS specific as it is not present in the PNS or in a variety of non-neuronal tissues. In addition, the size of the doublet, at least in the adult, is region specific. The forebrain and spinal cord express a doublet centered at about $80 \mathrm{kDa}$, while the molecular weight of the doublet in the cerebellum is slightly smaller. This size disparity could be due to the presence of additional carbohydrate on the forebrain/spinal cord proteins. It is also possible that the core proteins in each doublet are distinct. Several such region-specific carbohydrate-bearing antigens have been shown to be expressed during the early development of Drosophila, grasshopper (Snow et al., 1987), rat (Dodd et al., 1988), and chick (Canning and Stern, 1988; Roberts et al., 1991).

\section{Comparison with $m A b 52 G 9$}

As described in the Results, we find that mAb FORSE-1 and mAb 52G9 have identical labeling patterns in our hands. Some of our findings, like the staining of the telencephalon, olfactory bulb, nasal pits, otic placodes, and Rathke's pouch, agree with those of Stainier et al. (1991). Our other results, particularly the biochemical characterization of the antigen, the pattern of labeling in the forebrain, the transient, dorsoventrally restricted labeling of the entire CNS, and the presence of staining at E18 and beyond, arc very different from those previously reported for $\mathrm{mAb} 52 \mathrm{G} 9$. We do not, at any age, observe a single, restricted region of labeling in the diencephalon as was reported for $\mathrm{mAb} 52 \mathrm{G} 9$. Rather, this restricted region is part of the pattern we demonstrate in the diencephalon from E11.5 to E13.5 (Fig. $2 C$ ), which is clearly visualized in horizontal sections. Stainier et al. used sagittal sections, which do not permit visualization of each of the regions in a single section. Moreover, despite many variations in our methods, and replication of the methods of Stainier et al., neither $\mathrm{mAb}$ yields the $55 \mathrm{kDa}$ band on immunoblots of E15 forebrain that was reported by them.

\section{References}

Andrews PW (1984) Retinoic acid induces neuronal differentiation of a cloned human embryonal carcinoma cell line in vitro. Dev Biol 103:285-293.

Andrews PW, Damjanov I, Simon D, Banting G, Carlin C, Dracopoli N, Fogh J (1984) Pluripotent embryonal carcinoma clones derived from the human teratocarcinoma cell line TERA-2. Lab Invest 50: $147-162$

Andrews PW, Nudelman E, Hakomori S-I, Fenderson BA (1990) Different patterns of glycolipid antigens are expressed following differentiation of TERA-2 human embryonal carcinoma cells induced by retinoic acid, hexamethylene bisacetamide (HMBA) or bromodeoxyuridine (BUdR). Differentiation 43:131-138.

Bally-Cuif L, Goridis C, Santoni M-J (1993) The mouse NCAM gene displays a biphasic expression pattern during neural tube development. Development 117:543-552.

Barbe MF, Levitt P (1992) Attraction of specific thalamic input by cerebral grafts depends on the molecular identity of the implant. Proc Natl Acad Sci USA 89:3706-3710.

Bayer SA (1983) 3H-thymidine-radiographic studies of neurogenesis in the rat olfactory bulb. Exp Brain Res 50:329-340.

Bogarad LD, Utset MF, Awgulewitsch A, Miki T, Hart CP, Ruddle FH (1989) The developmental expression of a new murine homeobox gene: Hox-2.5. Dev Biol 133:537-549,

Bulfone A, Puelles L, Porteus MH, Frohman MH, Martin GR, Rubenstein JLR (1993) Spatially restricted expression of Dlx-1, Dlx-2(Tes-
1), Gbx-2, and Wnt-3 in the embryonic day 12.5 mouse forebrain defines potential transverse and longitudinal segmental boundaries. $J$ Neurosci 13:3155-3172.

Canning DR, Stern CD (1988) Changes in the expression of the carbohydrate epitope HNK-1 associated with mesoderm induction in the chick embryo. Development 104:1-13.

Chisaka O, Capecchi MR (1991) Regionally restricted developmental defects resulting from targeted disruption of the mouse homeobox gene hox-1.5. Nature 350:473-479.

Chisaka O, Musci TS, Capecchi MR (1992) Developmental defects of the ear, cranial nerves and hindbrain resulting from targeted disruption of the mouse homeobox gene Hox-1.6. Nature 355:516-520.

Cole GJ, McCabe CF (1991) Identification of a developmentally regulated keratan sulfate proteoglycan that inhibits cell adhesion and neurite outgrowth. Neuron 7:1007-1018.

Davis CA, Noble-Topham SE, Rossant J, Joyner AL (1988) Expression of the homeo box-containing gene En-2 delineates a specific region of the developing mouse brain. Genes Dev 2:361-371.

Dodd J, Morton SB, Karagogeos D, Yamamoto M, Jessell TM (1988) Spatial regulation of axonal glycoprotein expression on subsets of embryonic spinal neurons. Neuron 1:105-116.

Frohman MA, Boyle M, Martin GR (1990) Isolation of the mouse Hox2.9 gene; analysis of embryonic expression suggests that positional information along the anterior-posterior axis is specified by mesoderm. Development 110:589-607.

Fryer HJL, Kelly GM, Molinaro L, Hockfield S (1992) The high molecular weight Cat-301 chondroitin sulfate proteoglycan from brain is related to the large aggregating proteoglycan from cartilage, aggrecan. J Biol Chem 267:9874-9883.

Graham A, Papalopulu N, Lorimer J, McVey JH, Tuddenham EGD, Krumlauf R (1988) Characterization of a murine homeo box gene, Hox-2.6, related to the Drosophila deformed gene. Genes Dev 2:1424-1438.

Graham A, Maden M, Krumlauf R (1991) The murine Hox-2 genes display dynamic dorsoventral patterns of expression during central nervous system development. Development 112:255-264.

Gruss P, Walther C (1992) Pax in development. Cell 69:719-722.

Hawrot E, Patterson PH (1979) Long-term culture of dissociated sym pathetic neurons. Methods Enzymol 58:574-584.

Herndon ME, Lander AD (1990) A diverse set of developmentally regulated proteoglycans in the rat central nervous system. Neuron $4: 949-961$

Hogan BLM, Holland PWH, Lumsden A (1988) Expression of the homeobox gene, Hox 2.1, during mouse embryogenesis. Cell Differ Dev 25:39-44.

Hunt P, Gulisano M, Cook M, Sham M-H, Faiella A, Wilkinson D, Boncinelli E, Krumlauf R (1991a) A distinct Hox code for the branchial region of the vertebrate head. Nature 353:861-864.

Hunt P, Whiting I, Nonchev S, Sham M-H, Marshall H, Graham A, Cook M, Allemann R, Rigby PWJ, Guilisano M, Faiella A, Boncinelli E, Krumlauf R (1991b) The branchial Hox code and its implications for gene regulation, patterning of the nervous system and head evolution. Development [Suppl] 2:63-77.

Jones FS, Prediger EA, Bittner DA, DeRobertis EM, Edelman GM (1992) Cell adhesion molecules as targets for Hox genes: neural cell adhesion molecule promoter activity is modulated by cotransfection with Hox-2.5 and -2.4. Proc Natl Acad Sci USA 89:2086-2090.

Kohler G, Milstein C (1975) Continuous cultures of fused cells secreting antibody of defined specificity. Nature 256:495-497.

Krumlauf $R$ (1993) Hox genes and pattern-formation in the branchial region of the vertebrate head. Trends Genet 9:106-122.

Krumlauf R, Holland PWH, McVey JH, Hogan BLM (1987) Developmental and spatial patterns of expression of the mouse homeobox gene, Hox 2.1. Development 99:603-617.

Kuratani SC, Eichele G (1993) Rhombomere transplantation repatterns the segmental organization of cranial nerves and reveals cell-autonomous expression of a homeodomain protein. Development 117:105117.

Laemmli UK (1970) Cleavage of structural proteins during the assembly of the head of bacteriophage T4. Nature 227:680-685.

Lazzaro D, Price M, DeFelice M, DiLauro R (1991) The transcription factor TTF-1 is expressed at the onset of thyroid and lung morphogenesis and in restricted regions of the foetal brain. Development 113:1093-1104

Lo L-C, Johnson JE, Wuenschell CW, Saito T, Anderson DJ (1991) 
Mammalian achaete-scute homolog 1 is transiently expressed by early neuroepithelial and neural crest cells. Genes Dev 5:1524-1537.

Lowry OH, Rosebrough NJ, Farr AL, Randall RJ (1951) Protein measurement with the Folin phenol reagent. J Biol Chem 193:265-275.

Lu S, Bogarad LD, Murtha MT, Ruddle FH (1992) Expression pattern of a murine homeobox gene, Dbx, displays extreme spatial restriction in embryonic forebrain and spinal cord. Proc Natl Acad Sci USA 89: 8053-8057.

Lufkin T, Dierich A, LeMeur M, Mark M, Chambon P (1991) Disruption of the Hox-1.6 homeobox gene results in defects in a region corresponding to its rostral domain of expression. Cell 66:1105-1119.

Lumsden A, Keynes R (1989) Segmental patterns of neuronal development in the chick hindbrain. Nature 33:424-428.

Maeda N, Matsui F, Oohira A (1992) A chondroitin sulfate proteoglycan that is developmentally regulated in the cerebellar mossy fiber system. Dev Biol 151:564-574.

Matthew WD, Patterson PH (1983) The production of a monoclonal antibody that blocks the action of a neurite outgrowth-promoting factor. Cold Spring Harbor Symp Quant Biol 48:625-631.

Matthew WD, Sandrock AW (1987) Cyclophosphamide treatment used to manipulate the immune response for the production of monoclonal antibodies. J Immunol Methods 100:73-82.

Mavilio F, Simeone A, Boncinelli E, Andrews PW (1988) Activation of four homeobox gene clusters in human embryonal carcinoma cells induced to differentiate by retinoic acid. Differentiation 37:73-79.

McConnell SK, Kaznowski CE (1991) Cell cycle dependence of laminal determination in developing neocortex. Science 254:282-285.

Oohira A, Matsui F, Matsuda M, Takida Y, Kuboki Y (1992) A chondroitin sulfate proteoglycan that is developmentally regulated in the cerebellar mossy fiber system. Dev Biol 151:564-574.

Ou SK, McDonald C, Patterson PH (1991) Comparison of two techniques for targeting the production of monoclonal antibodies against particular antigens. J Immunol Methods 145:111-118.

Patterson PH (1992) New methods in immunology, short course 1, pp 1-13. Anaheim, CA: Society for Neuroscience.

Porteus MH, Bulfone A, Ciaranello RD, Rubenstein JLR (1991) Isolation and characterization of a novel cDNA clone encoding a homeodomain that is developmentally regulated in the ventral forebrain. Neuron 7:221-229.

Price M, Lemaistre M, Pischetola M, DiLauro R, Duboule D (1991) A mouse gene related to Distal-less shows a restricted expression in the developing forebrain. Nature 351:748-750.

Price M, Lazzaro D, Pohl T, Mattei M-G, Ruther U, Olivo J-C, Duboule D, DiLauro R (1992) Regional expression of the homeobox gene Nkx-2.2 in the developing mammalian forebrain. Neuron 8:241-255.

Roberts C, Platt N, Streit A, Schachner M, Stern C (1991) The L5 epitope: an early marker for neural induction in the chick embryo and its involvement in inductive interactions. Development 112:959970.

Robinson GW, Wray S, Mahon KA (1991) Spatially restricted expres- sion of a member of a new family of murine Distal-less homeobox genes in the developing forebrain. New Biol 3:1183-1194.

Salinas PC, Nusse R (1992) Regional expression of the Wnt-3 gene in the developing mouse forebrain in relationship to diencephalic neuromeres. Mech Dev 39:151-160.

Schughart K, Utset MF, Awgulewitsch A, Ruddle FH (1988) Structure and expression of Hox-2.2, a murine homeobox-containing gene. Proc Natl Acad Sci USA 85:5582-5586.

Simeone A, Acampora D, Arciconi L, Andrews PW, Boncinelli E, Mavilio F (1990) Sequential activation of HOX2 homeobox genes by retinoic acid in human embryonal carcinoma cells. Nature 346:763766.

Simeone A, Acampora D, Gulisano M, Stornaiuolo A, Boncinelli E (1992a) Nested expression domains of four homeobox genes in developing rostral brain. Nature 358:687-690.

Simeone A, Gulisano M, Acampora D, Stornaiuolo A, Rambaldi M, Boncinelli E (1992b) Two vertebrate homeobox genes related to the Drosophila empty spiracles gene are expressed in the embryonic cerebral cortex. EMBO J 11:2541-2550.

Snow PM, Patel NH, Harrelson AL, Goodman CS (1987) Neural-specific carbohydrate moiety shared by many surface glycoproteins in Drosophila and grasshopper embryos. J Neurosci 7:4137-4144.

Stainier DYR, Bilder DH, Gilbert W (1991) Spatial domains in the developing forebrain: developmental regulation of a restricted cell surface protein. Dev Biol 147:22-31.

Streit A, Faissner A, Gehrig B, Schachner M (1990) Isolation, biochemical characterization of a neural proteoglycan expressing the L5 carbohydrate epitope. J Neurochem 55:1494-1506.

Taggart RT, Samloff IM (1983) Stable antibody-producing murine hybridomas. Science 219:1228-1230.

Tao W, Lai E (1992) Telencephalon-restricted expression of BF-1, a new member of the HNF-3/fork head gene family, in the developing rat brain. Neuron 8:957-966.

Tole S, Patterson PH (1995) Regionalization of the developing forebrain: a comparison of FORSE-1, Dlx-2, and BF-1. J Neurosci 15 : 970-980.

Vogels R, DeGraaff W, Deschamps J (1990) Expression of the murine homeobox-containing gene Hox-2.3 suggests multiple time-dependent and tissue-specific roles during development. Devclopment 110 $1159-1168$

Walther C, Gruss P (1991) Pax-6, a murine paired box gene, is expressed in the developing CNS. Development 113:1435-1449.

Wilkinson DG, Bhatt S, Chavrier P, Bravo R, Charnay P (1989) Segment-specific expression of a zinc-finger gene in the developing nervous system of the mouse. Nature 337:461-464.

Wilson SW, Placzek M, Furley AJ (1993) Border disputes: do boundaries play a role in growth-cone guidance? Trends Neurosci 16:316323

Zaremba S, Guimaraes A, Kalb RG, Hockfield S (1989) Characterization of an activity-dependent, neuronal surface proteoglycan identified with monoclonal antibody Cat-301. Neuron 2:1207-1219. 